\title{
RECIENTES APORTACIONES AL URBANISMO BAJOMEDIEVAL DE CREVILLENT (ALICANTE): EL CEMENTERIO MUDÉJAR DEL RAVAL
}

\author{
RECENT CONTRIBUTIONS TO THE LATE MEDIEVAL URBANISM OF CREVILLENT (ALICANTE): THE \\ MUDEJAR CEMETERY OF EL RAVAL
}

\author{
JULIO TRELIS MARTI \\ Museo Arqueológico Municipal de Crevillent \\ JOSÉ RAMÓN ORTEGA PÉREZ \\ DANIEL TEJERINA ANTÓN \\ MARCO AURELIO ESQUEMBRE BEBIA \\ ARPA Patrimonio
}

\begin{abstract}
Resumen. Unas obras de rehabilitación en el sector oriental del Casco Antiguo de Crevillent (Alicante), han permitido localizar parcialmente una necrópolis mudéjar encuadrada cronológicamente entre los siglos XIV-XV. Se han registrado 31 inhumaciones depositadas en estrechas fosas excavadas en la tierra, con individuos de diferentes edades, combinándose la colocación del cadáver en decúbito lateral derecho y decúbito supino. Este cementerio mudéjar se sitúa en las afueras del núcleo urbano y justo al lado de uno de los caminos de salida de la ciudad, colindando con el denominado "raval" núcleo de población islámica de origen feudal (S. XIV). Hemos podido datar por C- 14 los restos óseos de dos sepulturas, así como presentar anexo el estudio osteoarqueológico de cada enterramiento, suponiendo todo un avance en la investigación de los espacios funerarios islámicos, de difícil definición. A nivel de Crevillent, esta excavación supone un hito en la arqueología urbana y en el conocimiento de su urbanismo medieval.

Palabras clave. Crevillent, El Raval, Baja Edad Media, necrópolis, mudéjar
\end{abstract}

\begin{abstract}
Recent renovation work in the eastern part of the old quarter of Crevillent (Alicante) has revealed part of a Mudejar cemetery dating to the 14th and 15th centuries. 31 inhumations deposited in narrow ditches have been carefully recorded. Several individuals of different ages have been found, in right lateral decubitus position and supine position. This Mudejar cemetery is located on the outskirts of the town centre, beside one of the roads out of the town, next to the "Raval" Islamic quarter of the feudal period (14th Century). We have been able to date bones from two graves (by C-14), and include an osteoarchaeological study of each burial as an annex. This a big step forward in the research of Islamic funerary spaces, whose definition is difficult. This excavation is a milestone in Urban Archaeology for the Crevillent area, and an understanding of its medieval urbanism.
\end{abstract}

Key words. Crevillent, El Raval, Late Middle Ages, cemetery, Mudejar

En 2005, con ocasión de las obras de "Rehabilitación del Casco Antiguo de Crevillent (Alicante). Sectores San Joaquín y Plaza Pare Palau", se realizaron unas excavaciones arqueológicas en dicha plaza al objeto de documentar arqueológicamente determinadas noticias orales acerca de la ubicación de la ermita de Santa Anastasia, así como restos óseos humanos que aparecieron al hacer las cimentaciones de los edificios de la zona.

Dicha plaza se halla al Este del núcleo más antiguo de la ciudad. Junto a la misma se localiza un edificio del siglo XVIII, conocido por el Hospital. La intervención arqueológica se realizó bajo el asfaltado de la plaza y frente al ingreso del antiguo hospital, en un pequeño jardín con palmeras (Fig. 2).

En la actuación sobre la plaza se pudo documentar la planta rectangular de la antigua ermita, de una sola nave, con presbiterio y altar mayor en su cabecera, un altar lateral y al Sur el acceso compuesto por dos quiciales de una puerta de dos hojas, destacando el pavimento de losetas de cemento hidráulico en blanco y negro que crean composiciones cuadradas y cruciformes (Fig. 3). Se trata de la ermita de Santa Anastasia, de esta manera, si bien sus niveles 


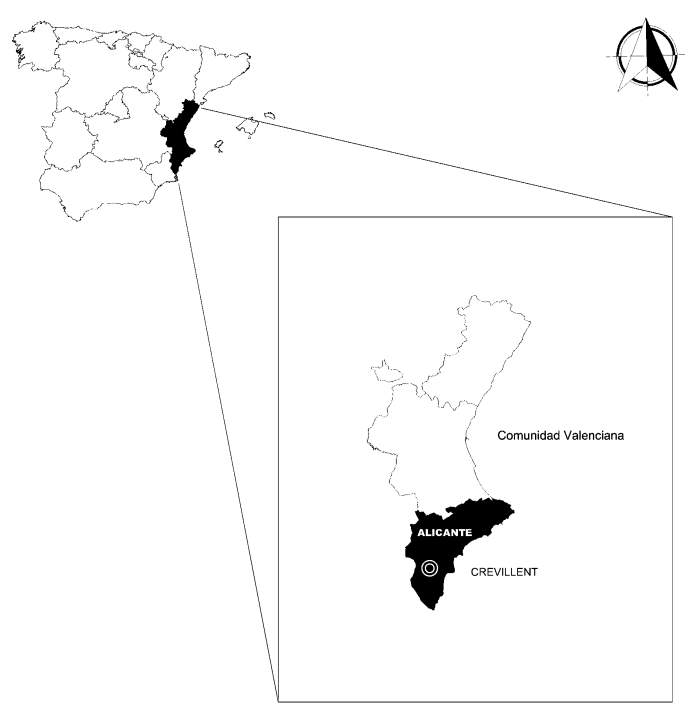

Figura 1: Situación de Crevillent (Alicante), dentro del contexto nacional, regional y provincial.

fundacionales del siglo XVIII no se conservan, se han documentado los restos de los siglos XIX y XX, previos a su destrucción en 1936. La documentación escrita y la arqueológica confirman la estrecha relación con el edificio del Hospital contiguo; tanto es así, que su pared medianera posiblemente sea la actual fachada de dicho edificio que da a la plaza Pare Palau (Fig. 2), lo cual se corroborará cuando se lleven a cabo las oportunas actuaciones en el mismo.

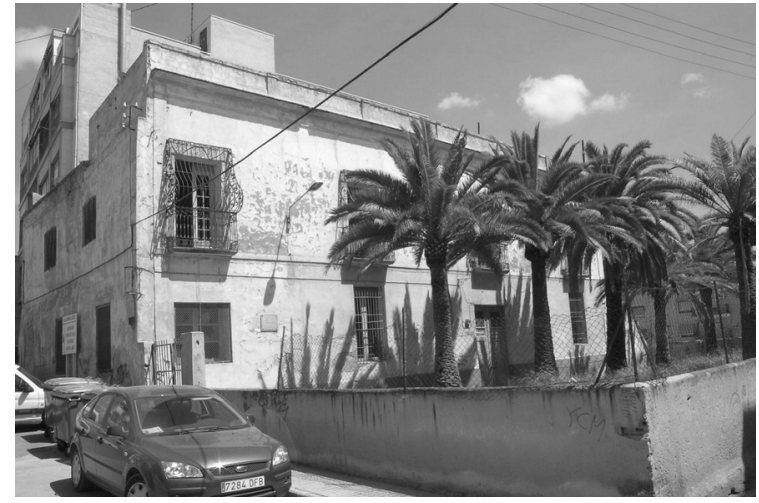

Figura 2: La actuación arqueológica se realizó en torno al antiguo edificio del Hospital en la plaza Pare Palau.

La intervención en el patio del Hospital, por su parte, nos permitió documentar parte de un cementerio mudéjar que analizaremos en mayor profundidad a continuación.

\section{CREVILLENT A LO LARGO DE LA EDAD MEDIA}

Sin contar con varios restos ibéricos, escasamente caracterizados, documentados en recientes excavaciones en el solar que hoy ocupa el casco urbano de Crevillent (Trelis y Molina, 2001; Trelis et alii, 2004), así como las noticias sobre diversos hallazgos epigráficos y numismáticos romanos recogidos en la historia de Montesinos

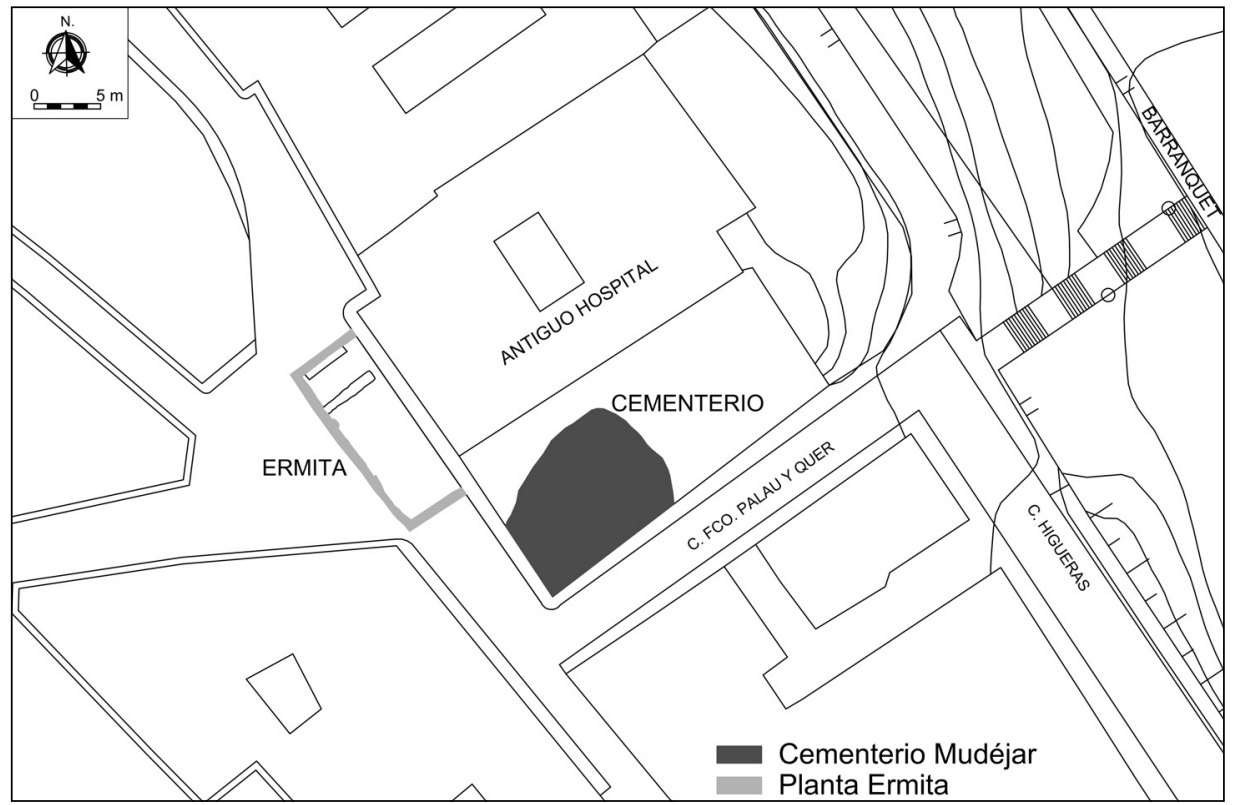

Figura 3: La intervención arqueológica permitió documentar la antigua ermita de Sta. Anastasia y un área funeraria mudéjar. 


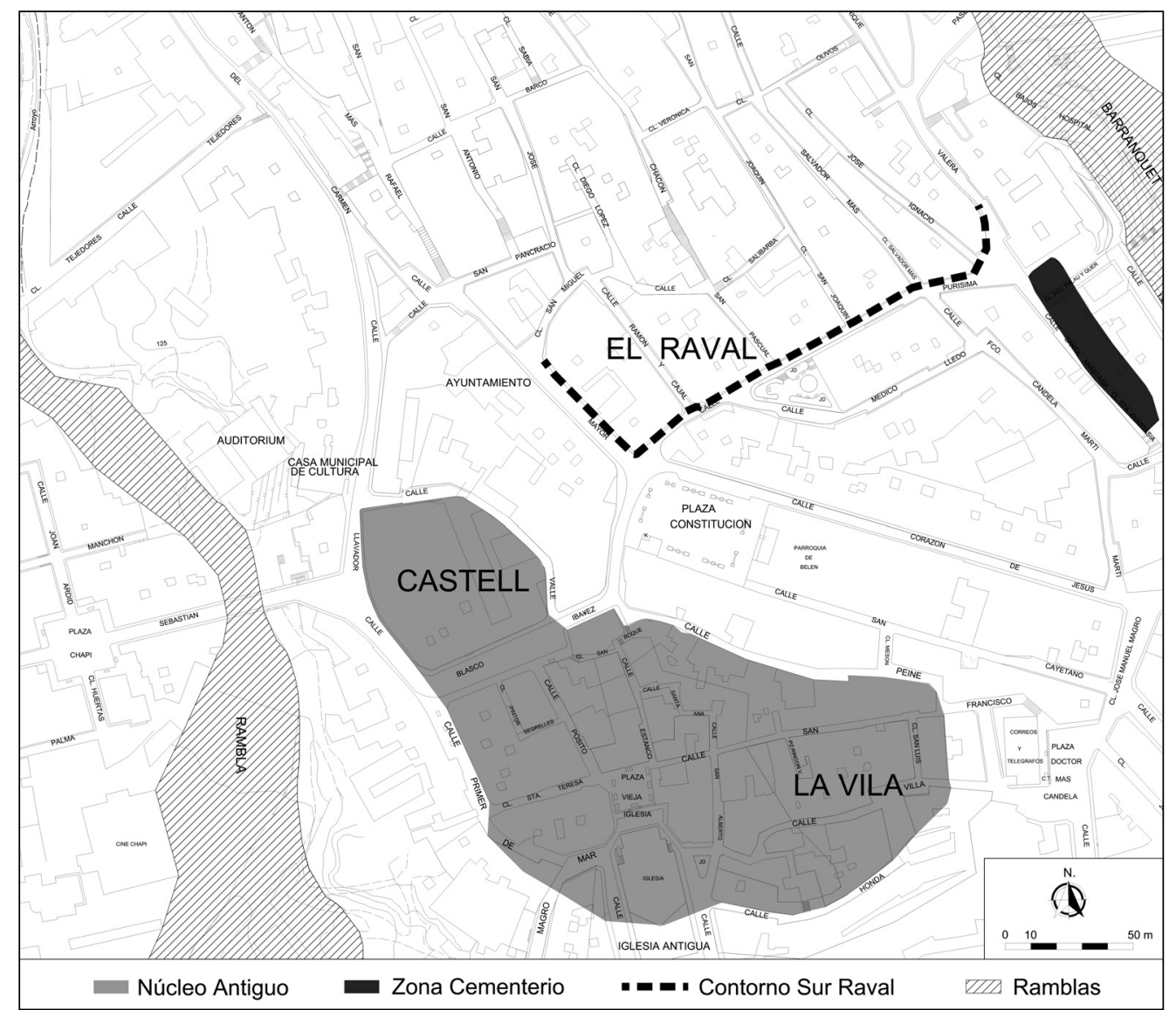

Figura 4: Plano histórico de Crevillent, donde se marcan aproximadamente los límites de su Vila Vella, el Castell, el Raval y el área del cementerio mudéjar.

(1740, 6-11), se puede afirmar con toda certeza que el origen del núcleo urbano actual es una fundación islámica. Para su precisa adscripción se cuenta, en primer lugar, con que no figura entre las ciudades del Pacto de Teodomiro de Orihuela (713). Es al-Idrīsī, geógrafo de mediados del siglo XII, quien cita por primera vez un "hiș̣n Qaribliyān" (Mizal, 1989). Otras citas corresponden a Al-Himyari en el siglo XIV, quien se refiere a la agricultura y al sistema de abastecimiento de agua (Lévi-Provençal, 1938). Por otra parte, las excavaciones en la Villa Vella ofrecen unas dataciones que están en sintonía con las citas mencionadas, destacando entre finales del siglo XII y primera mitad del siglo XIII para el vertedero almohade de la calle Peine 6-10, y el siglo XIV para el abandono de las viviendas almohades de la calle Villa 34 (Trelis y Molina, 2001; Trelis et alii, 2004), ambos hallazgos localizados en lo que parece ser la zona perimetral del núcleo urbano. Posiblemente su origen esté relacionado con el aumento de la fiscalidad de fines del siglo $X$ y de los gobiernos taifas que empobrecieron a la población campesina de los territorios castrales y obligaron a abandonar los antiguos poblados fortificados o hușūn y trasladarse a los núcleos urbanos, adquiriendo un desarrollo notable, como ocurre en otros lugares del Vinalopó (Azuar, 1995, 219).

De este modo, Qaribliyān quedaba sentado sobre una elevación bien delimitada a Poniente por el cauce encajado de la Rambla del Castellar, y lo integraba un castillo -castrum citado en las fuentes cristianas-, el cual se localizaba sobre una pequeña elevación en lo que hoy es el cine Iris, y lo que sería la medina a sus pies, entre éste y el cauce de la mencionada rambla al Oeste (Fig. 4). Tras la expulsión de los moriscos en 1609 y sobre todo a partir de la explosión demográfica del siglo XVIII, este núcleo urbano sufriría considerables transformaciones; los estudios arqueológicos realizados hasta la fecha dan a entender que dicha elevación sería truncada a base de nivelaciones, quedando, por tanto, como testigos del urbanismo medieval sólo las zonas marginales.

Vicente Gozálvez ha sido el investigador que ha realizado un estudio en conjunto sobre la 


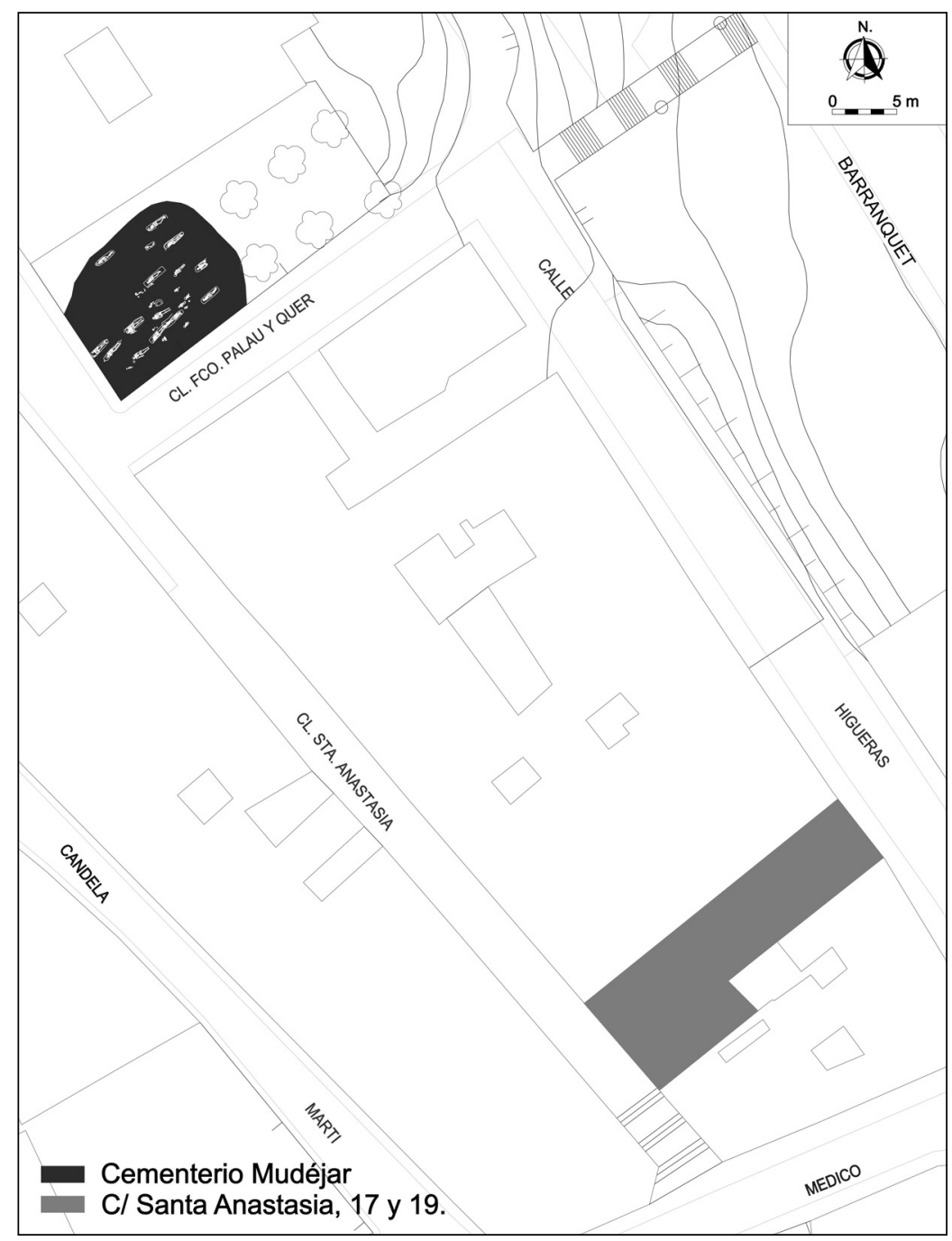

Figura 5: Plano de localización del área cementerial en el entorno de la plaza Pare Palau y el solar de la C/ Sta Anastasia $n^{\circ} 17$ y 19 , donde se han encontrado recientemente restos óseos de varias sepulturas seccionadas.

evolución del casco urbano de Crevillent. En el mismo estima que el perímetro para mediados del siglo XVI estaría en torno a las actuales calles de Estanco, S. Alberto, Rincón Villa y Plaza Iglesia Vieja (Gozálvez, 1983, 21, Fig. 3).

Otra visión sobre el urbanismo, en este caso sólo medieval, es la de Josep Menargues. Según él, a finales del siglo XIV Crevillent estaba compuesto por un castillo con una ciudadela subcastral, defendida por torres como la de l'Adarop; y el núcleo urbano que a su vez lo formaba la Vila Vella, con cierres y muros, y el Raval (Menargues, 2005, 249). Este raval ocuparía lo que hoy es el barrio de San Joaquín, que le da nombre, y le atribuye un origen feudal (Menargues, 2002, 264). Junto al raval y en dirección a Levante, cerca del lugar conocido por "el barranquet", sitúa un cementerio o "ma- qbara" islámico (Menargues, 2002, 265 y 2004, 236) (Fig. 5).

Relacionado con ellos contamos con un documento del primer cuarto del siglo XVII donde se cita: "... una casa situada en el Raval de la Villa al cabo de la calle del cementerio de los moros ...", el cual viene a constatar la existencia de ambos'.

Bajo este techo vivió una población musulmana con sus diferentes aconteceres hasta que en 1243 Castilla conquista el Reino de Murcia y

1. Capbreve del año $1624-25$ del notario D. Joseph Cecilia, conservado en el Archivo Histórico Municipal de Elche b 64, f. 82. Nuestro agradecimiento a Salvador Puig por habernos facilitado este documento inédito, así como por las orientaciones para la realización de las actuaciones arqueológicas y su documentación. 
con él Crevillent. Esta conquista se realizó por medio del reconocimiento de unos protectorados cristianos a cambio de respetar los derechos de diversos arraeces. En 1296, Jaime II ocuparía las tierras del Reino de Murcia, quedándose al fin sólo las del Sur de la provincia de Alicante, por lo que Crevillent pasaría a manos de la Corona Catalanoaragonesa. La política de protectorados no resultó todo lo positiva que se deseaba, por lo que, tras varias rebeliones y demás problemas, a finales del siglo XIII estos protectorados habían desaparecido, excepto el de Crevillent que perduró hasta 1318.

Pierre Guichard (1976) ha sido quien ha dedicado un trabajo monográfico a este tema. En él enumera, entre otros privilegios del ra'is de Crevillent, el derecho de justicia de los musulmanes de Orihuela y parte nordeste del Reino de Murcia, así como el nombramiento de alamín y recaudador de la peyta, gozando en general de amplios poderes, concesiones y diferentes propiedades. Crevillent en este momento jugó un papel de intermediario con las comunidades musulmanas de su entorno más próximo (valle del Vinalopó, Ricote, etc.) y por supuesto con el Reino de Granada; ahí es donde posiblemente esté la razón de ser de este señorío tan vetusto (Guichard, 1976, 31).

El devenir de Crevillent durante la Baja Edad Media está caracterizado por el origen de su población, casi exclusivamente musulmana, por su situación fronteriza, tanto en lo que respecta a Granada como a Castilla, y por estar involucrada en las célebres guerras entre Castilla y Aragón.

Se cuenta con varias estimaciones sobre cifras de la población, si bien es muy difícil reconocer con precisión el número de cristianos. Estos se reducirían a los oficiales de la administración y una guarnición. En el "Capbreve levador de Crevillent" de 1457, en el que aparecen las rentas que recibía Barcelona de Crevillent en el período en que ésta y Elche fueron vendidas a la ciudad condal, sólo constan tres cristianos (Garrido, 2003, 25)2. Para Ferrer Mallol (1988a, 52-53) la población en el siglo XV sería superior a 430 habitantes, obteniéndola entre los impuestos de cabeçatge y gallines -351 y 251 habitantes respectivamente para 1461- y l'almagram $-375 / 437$ habitantes para mediados del siglo XV-. Hinojosa (1989, 310-312) hace lo propio para un periodo que va entre 1399 y 1465 , a par-

2. Arxiu Històric de la Ciutat de Barcelona, 1C-XII-24, cuaderno suelto. tir de los impuestos del morabatín, cabeçatge, gallines y alfatrà, de los cuales la cifra más baja corresponde a 1399 -329 habitantes- y la más alta a $1461-481$ habitantes-, destacando que los arrendadores son siempre musulmanes, sin aparecer nombres cristianos en estos años. Los censos de Lapeyre (1959, 43-90), por último, dan una cifra de 938 habitantes en 1563, 1800 para momentos antes de la expulsión de los moriscos en 1609 y 873 para 1646. Estos datos dan una idea de lo que supuso la expulsión de los moriscos, lo cual afectaría de modo significativo al urbanismo de Crevillent, tanto es así que el crecimiento urbano, en palabras de Vicente Gozálvez $(1983,24)$, incluso retrocediera.

La aljama crevillentina estaba regida por dos viejos, un consejo y un cadí que a partir de 1360 es el mismo que para Elche (Garrido, 2003, 20).

Quejas, ataques, injusticias y agravios comparativos, en general, de los cristianos contra los sarracenos crevillentinos serían hechos muy habituales en esta época. A ello hay que sumar las distinciones de tipo cultural y religioso, como la prohibición de relaciones sexuales, el vestido y el peinado. El abuso en el cobro de rentas preocupaba a las autoridades locales de Crevillent por el malestar que producía en la aljama (Garrido, 1997, 18).

En momentos de tensión fueron muy frecuentes las restricciones a la libertad de movimientos. Fijar su residencia resultaba muy difícil, en estas comarcas sobre todo por su proximidad a Granada y por su colaboración con los famosos salteadores o "collerats", lo cual tuvo también repercusiones económicas, pues se les prohibía recoger leña, sosa, esparto, etc.. Llegaron incluso a sufrir ataques como los del apellido de Elche en 1385 y 1388, lo cual provocó el deseo de abandonar la población definitivamente ( $\mathrm{Fe}$ rrer, 1988b, 24 y 37 ).

Las incursiones de tropas granadinas provocaron asimismo muchas agitaciones, entre las que cabe destacar las de Ridwan en 1332 que obligaron a los sarracenos de Crevillent a marcharse a Granada. Asimismo, en 1383, ante los rumores de una posible guerra con Granada, I'Infant Martí toma como precaución a mujeres y niños, llevándoselos a Elche, y deja a los sarracenos para que defiendan el castillo. La documentación cristiana, siempre que se dan este tipo de situaciones, nos indica que prefieren huir antes que revolucionarse, muestra del pesimismo respecto a su futuro. (Ferrer, 1988b, 46, 31 y 134).

Pero mucho más importantes serían las convulsiones a las que estuvieron expuestos, en 


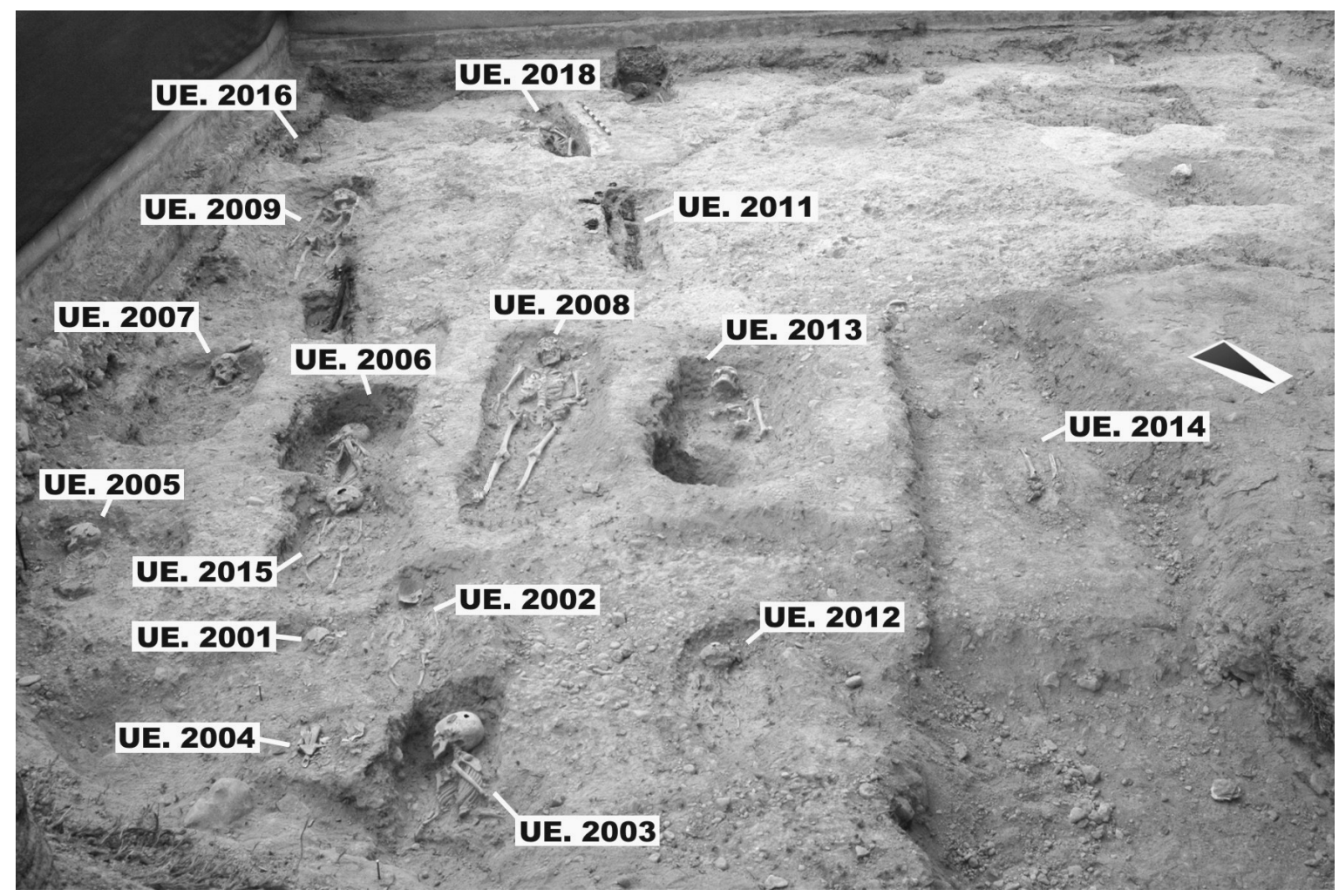

Figura 6: Conjunto de inhumaciones en proceso de excavación del cementerio mudéjar.
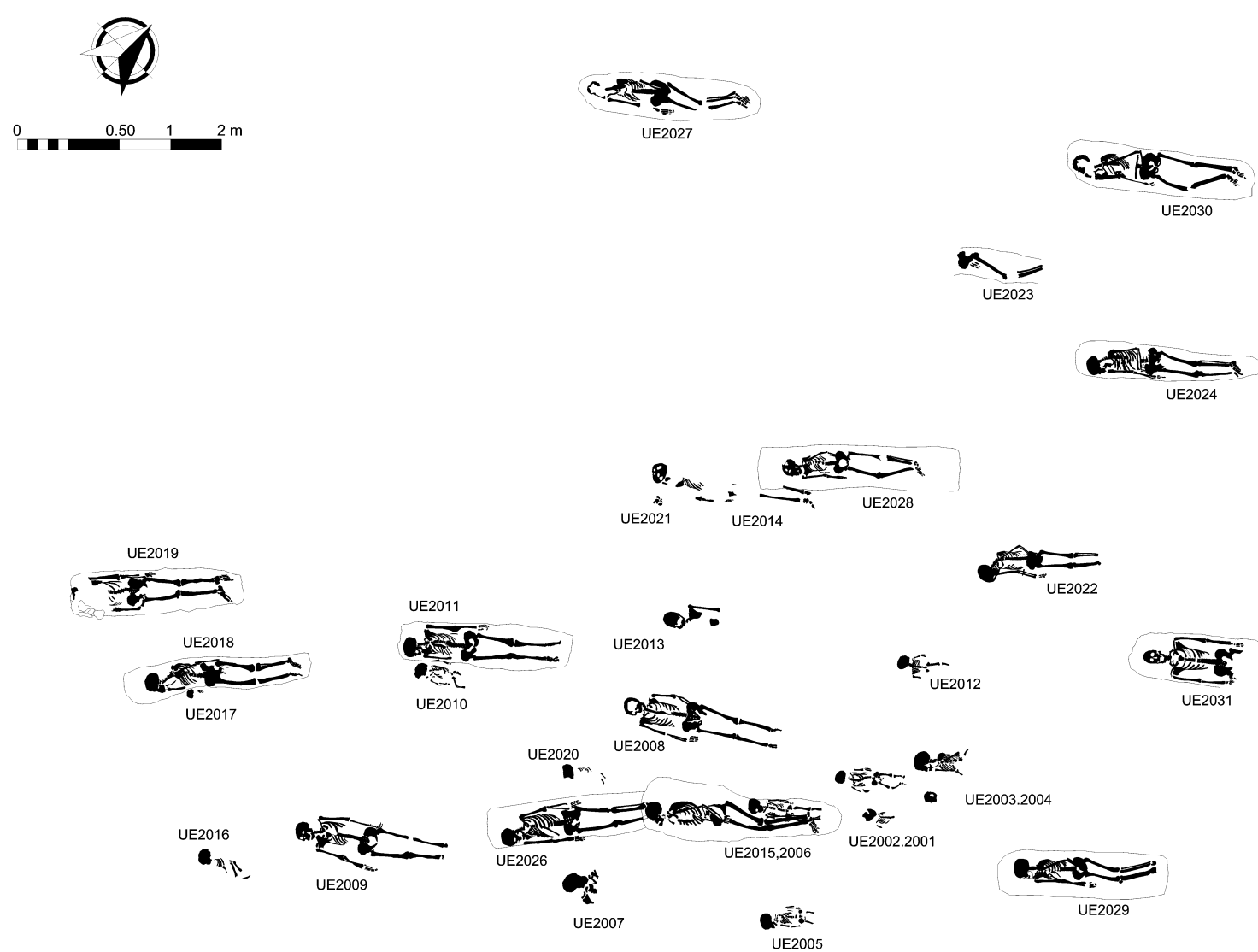

Figura 7: Planta con las diferentes sepulturas localizadas en la actuación arqueológica, pertenecientes a un gran cementerio mudéjar de Crevillent. 
ocasiones significativas, a consecuencia de las guerras con Castilla, ya mencionadas, quedando la población seriamente afectada. De ahí que se concedieran en varias ocasiones franquicias de impuestos y tierras a los que se establecieran en Elche y Crevillent, como las que otorgara la Reina Elionor en 1361 (Ferrer 1987, 126-127). En 1375 , ocupado Crevillent, una vez más, ya en el epílogo de la guerra castellana, se llevaron a los moros del lugar y hubo que rescatarlos, aunque no deseaban volver por miedo a las represalias de l'Infant Martí, que tuvo que exculparlos (Ferrer, 1988a, 71).

La emigración en un principio reportaba ingresos, porque tenían que pagar impuestos si se marchaban, y además dejaban las tierras libres para los cristianos y se alejaba el peligro de enfrentamientos de tipo étnico y cultural. Ahora bien, hacia mediados del siglo XIV comenzaron a ponerle freno por la Peste Negra, la Guerra con Castilla; y asimismo, por llevar cultivos a otros lugares, lo que aumentaba la competencia, y por dejar las tierras incultas. Un Fuero de las Cortes de Valencia de 1403 consigue la prohibición a los sarracenos de emigrar fuera de las tierras de señorío y esto fue la tónica durante todo el siglo XV. Así las cosas, no quedaba otro recurso que la emigración clandestina, siendo la puerta de salida las zonas fronterizas como la del valle de Elda y en general las comarcas del Sur, por lo que fueron muchas las disposiciones a lo largo de este siglo prohibiendo o restringiendo la emigración interior de sarracenos valencianos hacia la Gobernación de Orihuela. Esto resultó un error, puesto que hubo un aumento demográfico que, con el tiempo y con otras razones de tipo político, condujeron a la expulsión de 1609 (Ferrer, 1987, 162-183).

\section{EL CEMENTERIO MUDÉJAR}

La excavación arqueológica del jardín del hospital nos llevó a localizar un conjunto de 31 inhumaciones en fosas que cortaban el estrato geológico (Fig. 6 y 7). En cuanto al estado de conservación del área excavada, debemos hacer una serie de consideraciones, en primer lugar, el espacio funerario se ha encontrado alterado, al hallarnos en una zona de jardín, con plantación actual de palmeras cuyas raíces han afectado a algunas de las sepulturas. Además, de forma histórica se reconocen remociones del terreno, ya que algunas de las fosas han sido parcialmente destruidas, por lo que a la hora del registro arqueológico se han constatado inhumaciones incompletas y

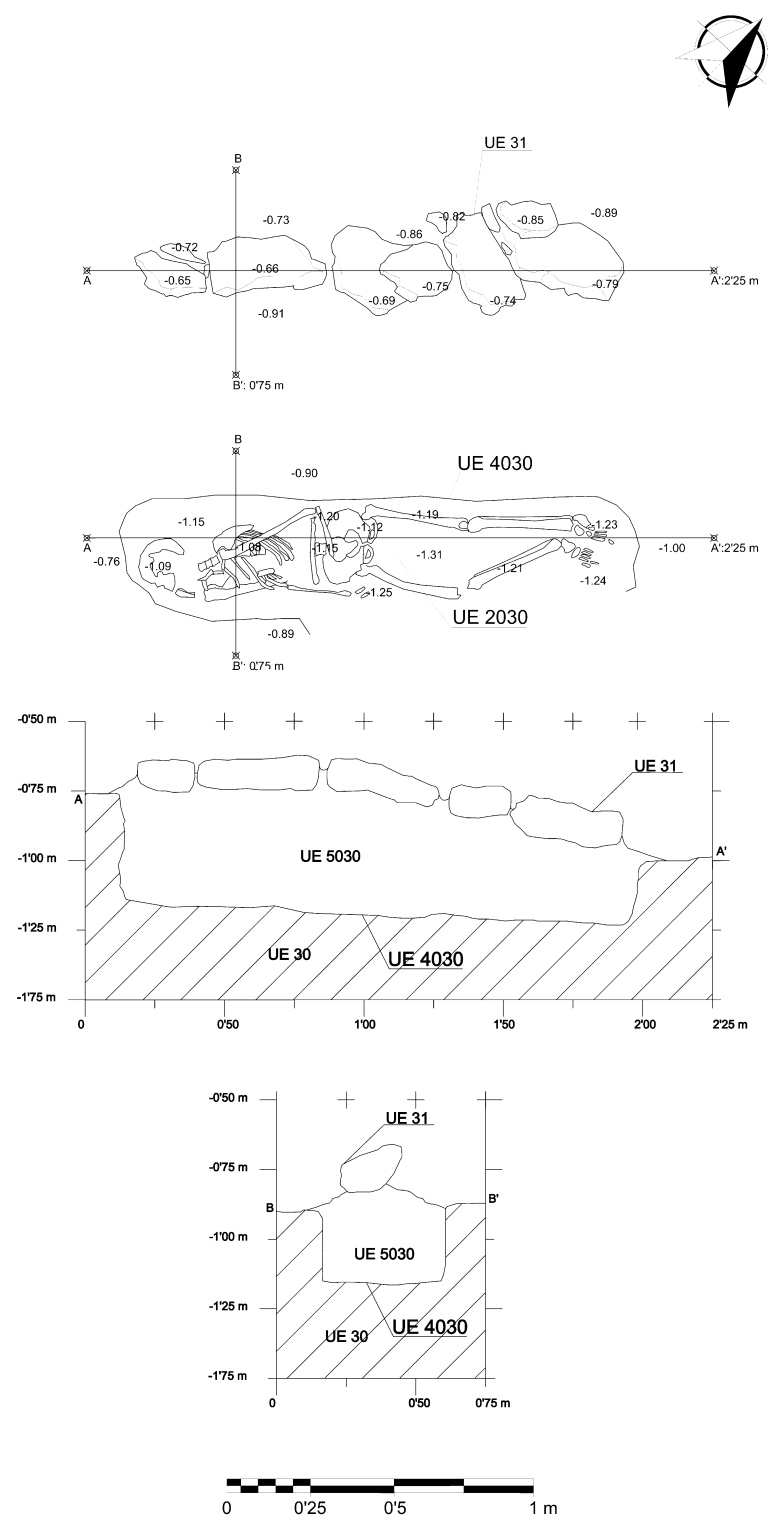

Figura 8: Planta y secciones de la sepultura UE 2030, única que conservaba parte de su cubierta con lajas de piedra.

el desplazamiento de huesos. Debemos reseñar la dificultad para definir los límites de las fosas, debido a la homogeneidad del terreno y las alteraciones postdeposicionales.

A pesar de ello, el área cementerial excavada nos ha ofrecido toda una serie de datos identificativos. Se trata de estrechas fosas excavadas directamente en la tierra, en cuyo interior se depositaban los cadáveres. Catorce de las fosas presentan una forma entre rectangular y ovalada, con secciones en $U$, en todos los casos; de las restantes no se ha podido reconocer su forma con exactitud. La anchura de las fosas varía entre 20 a $45 \mathrm{~cm}$, mientras que la longitud ha oscilado según si la inhumación es de un adulto o un 


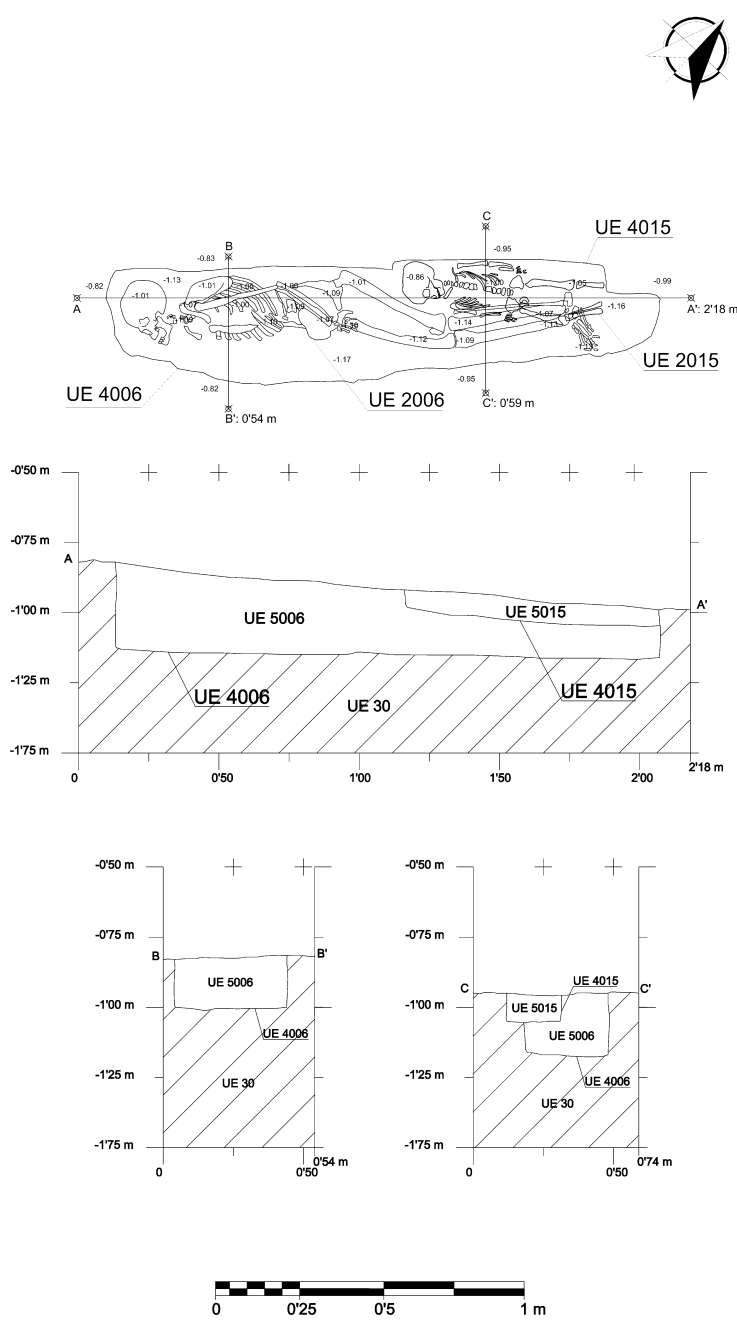

Figura 9: La superposición de enterramientos en esta necrópolis se observa entre la sepultura UE 2006, de un individuo masculino adulto maduro enterrado a una cota inferior, y otra sepultura superior la UE 2015 ubicada a los pies de la anterior, perteneciente a un individuo de unos 4 años. Planta y secciones de dichas sepulturas.

infantil, entre los primeros varía de 1,65 a 1,85 m, y entre los infantiles de $85 \mathrm{~cm}$ a $90 \mathrm{~cm}$. Respecto a la profundidad de las fosas suelen tener en torno a $50-60 \mathrm{cms}$. Sólo en un caso, la sepultura ha conservado parcialmente una cubierta de losas de piedra -UE 2030- (Fig. 8). Una hilada de losas rectangulares de mediano tamaño, dispuestas de forma plana en sentido longitudinal a la fosa, con una orientación SW-NE y unas dimensiones de $1,75 \mathrm{~m}$ de largo por $0,41 \mathrm{~m}$ de ancho. También destaca la aparición en la sepultura UE 2011 de una tabla de madera de unos $0,55 \mathrm{~m}$ de longitud por unos $3 \mathrm{~cm}$ de ancho, que posiblemente sería parte de su cubierta.

Se reconocen dos niveles de enterramientos, al documentarse fosas superpuestas a dife- rente cota, como ocurre en el caso de la sepultura UE 2006 de un varón adulto maduro enterrado en decúbito lateral derecho en un nivel inferior, con otro enterramiento superior sobre sus pies de tipo infantil colocado en decúbito supino -la sepultura UE 2015- (Fig. 9).

Las sepulturas excavadas pertenecen a individuos de diferentes edades, situados en diversas posiciones, documentándose 15 individuos enterrados en decúbito supino, 11 en decúbito lateral derecho y 5 imposible de definir. De los 31 individuos enterrados, 14 son infantiles, 2 de edad joven, 1 adulto joven, 8 adultos, 5 adultos maduros y 1 difícil de definir (UE 2027) entre juvenil-adulto joven. En lo que respecta al sexo, de nuevo, no existe un patrón por su ubicación o nivel, nos encontramos con 6 inhumaciones de mujeres, 6 de hombres y 19 sin determinar. Al relacionar la edad y el sexo de los inhumados, se observa el predominio de los individuos adultos masculinos, porcentaje que cambia en el caso de los adultos maduros, donde las mujeres suponen el $60 \%$ de los individuos identificados. Ese hecho constata la mayor longevidad de las mujeres.

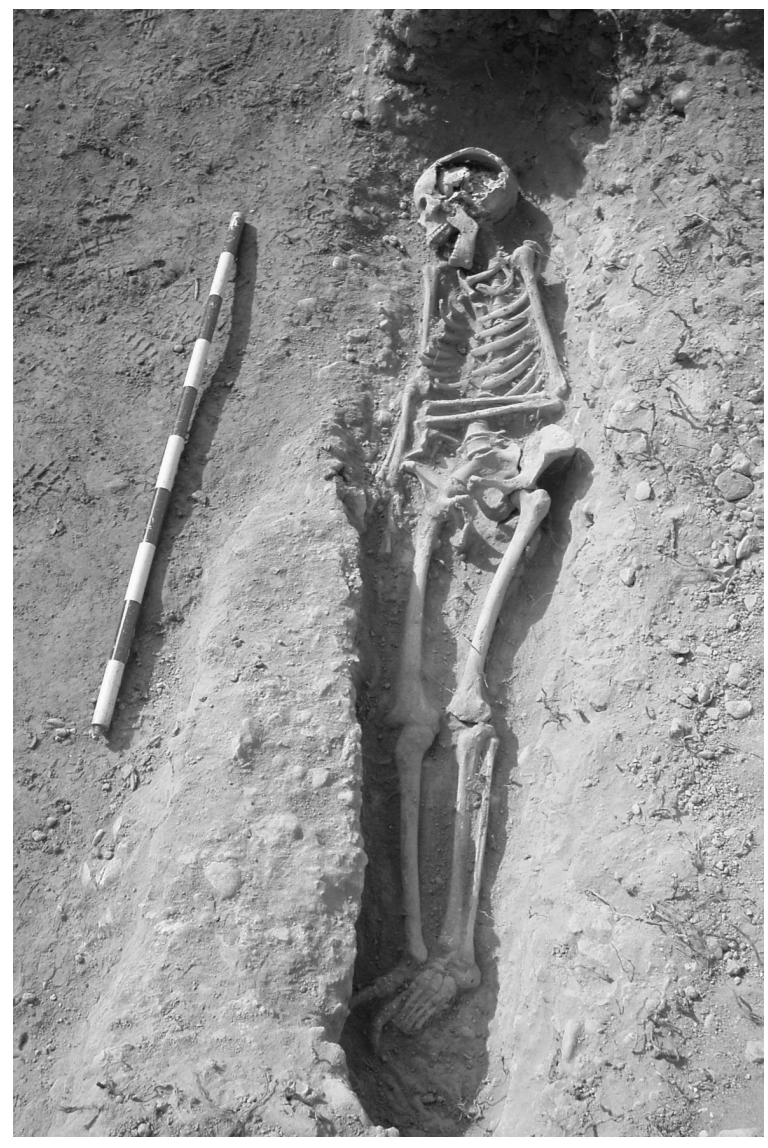

Figura 10: Sepultura UE 2024 con una mujer adulta joven enterrada en decúbito lateral derecho. 


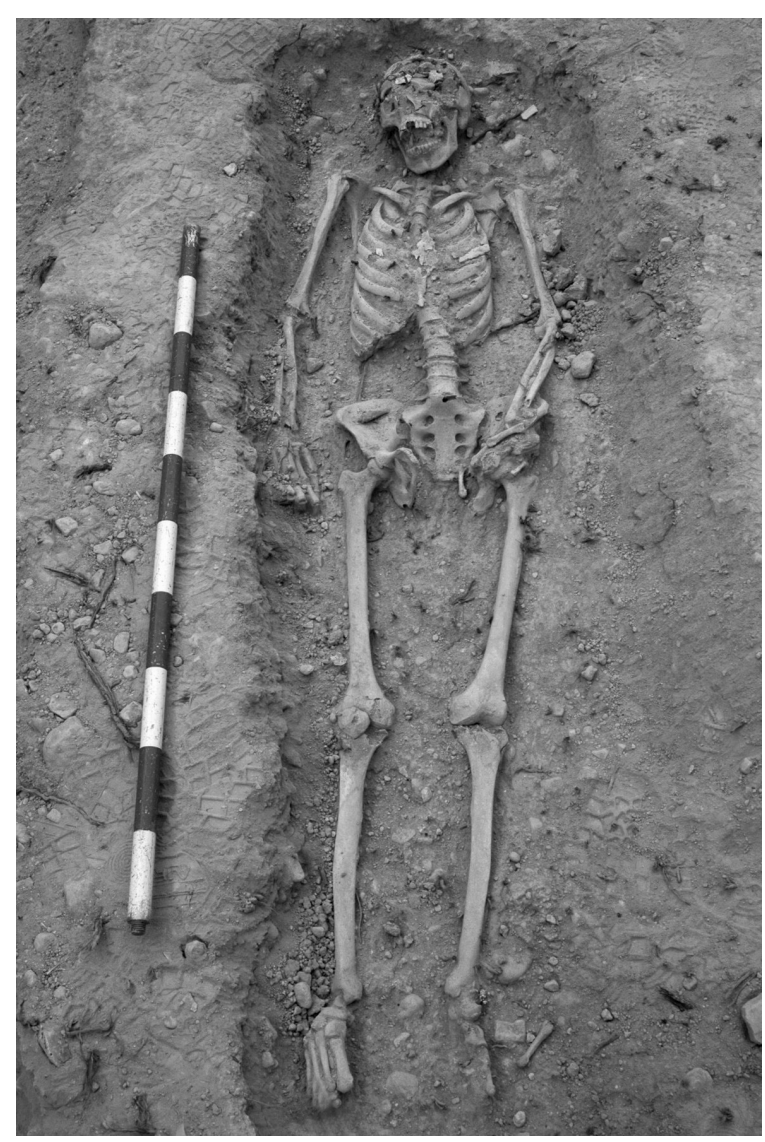

Figura 11: Sepultura UE 2008 con una mujer adulta madura enterrada en decúbito supino, que presenta la cabeza ligeramente ladeada hacia el Sureste.

Otros datos que nos ha aportado el estudio osteoarqueológico realizado por M. Paz de Miguel Ibáñez y que se presenta como anexo a este trabajo, es la existencia de un número elevado de muertos infantiles, sobre todo en sus primeras etapas, debido al riesgo en los partos y a los primeros momentos de vida, donde se registra una mayor mortalidad, generalizada en grupos de población antigua.

Se ha documentado entre los enterramientos algún individuo perinatal, como son unos fragmentos de huesos incompletos hallados en la sepultura UE 2017, un fémur y un radio dentro de la sepultura UE 2027, y un fémur localizado junto al esqueleto de un adulto (UE 2024). En el primer caso, nos hallamos ante una sepultura de un perinatal, mientras el resto de hallazgos están revueltos y no pueden vincularse a ninguno de los enterramientos, dada la gran alteración y fragmentación. Aunque no es descabellado pensar que se hallaran vinculados a alguna embarazada o fallecida tras el parto, hecho que simplemente anotamos sin darle consideración de afirmación.
A nivel de patologías detectadas en los individuos enterrados, debemos remarcar la constatación de que estamos ante una población con una dieta rica en hidratos de carbono (cereales) y escasa higiene bucal, que presenta algunos individuos con enfermedades metabólicas propiciadas por periodos de malnutrición y anemia. Otro elemento generalizado en este tipo de poblaciones de contexto rural es la existencia de artrosis y lesiones musculares, motivadas por los trabajos agrícolas y las actividades físicas forzosas. En nuestro caso, y a diferencia de lo documentado en otros cementerios coetáneos, destaca la carencia de traumatismos y fracturas en los individuos de esta necrópolis. Todos estos datos, deben ser valorados en su justa medida, ya que no debemos olvidar que sólo hemos documenta-

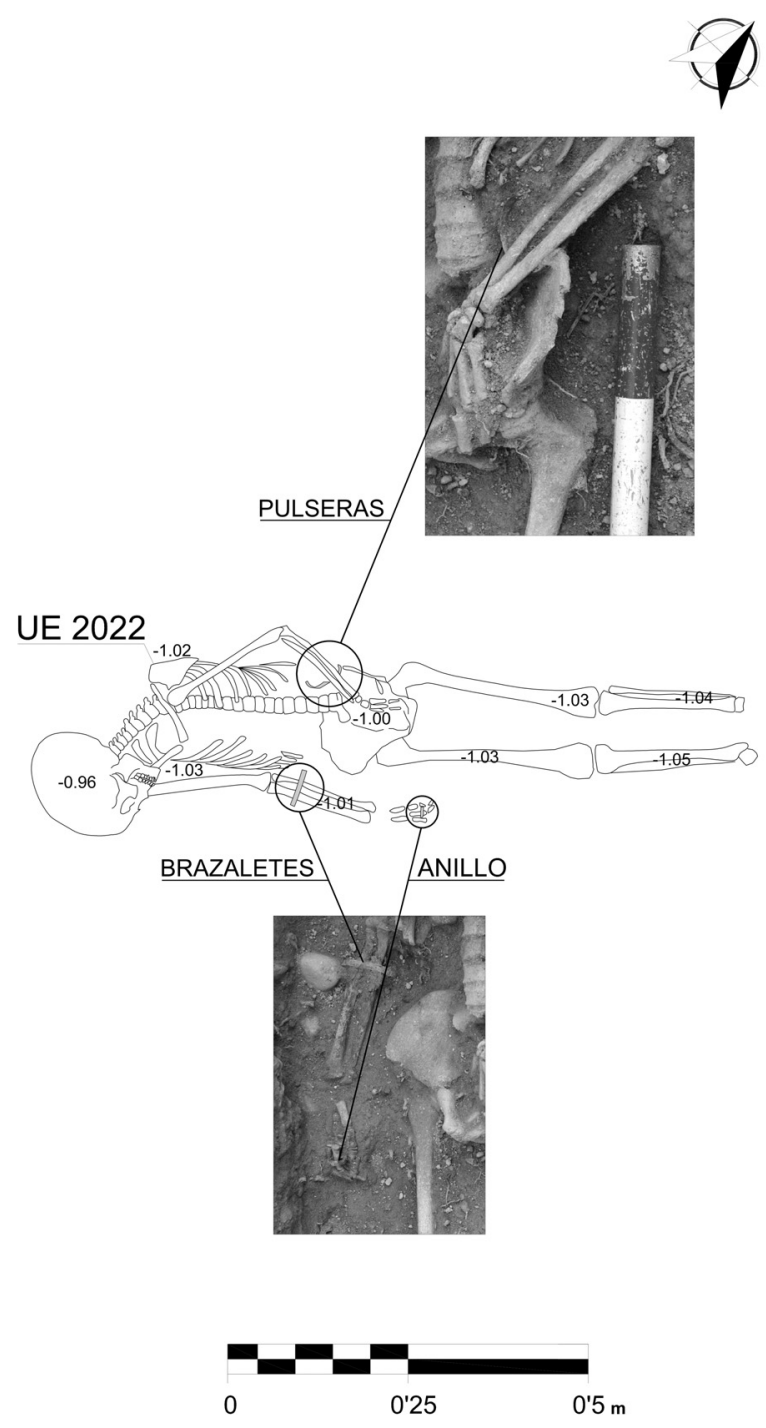

Figura 12: Una de las pocas sepulturas con ajuar, la UE 2022, que conservaba dos pulseras, dos brazaletes y un anillo, todos ellos de bronce. 


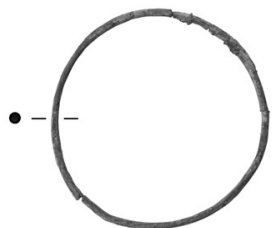

1

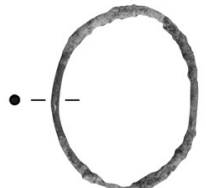

2

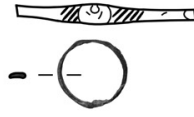

3
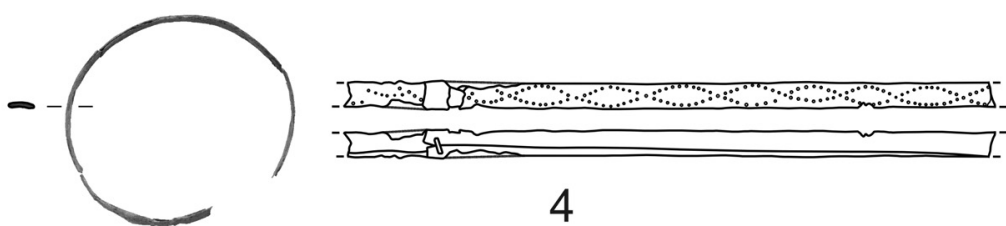

4
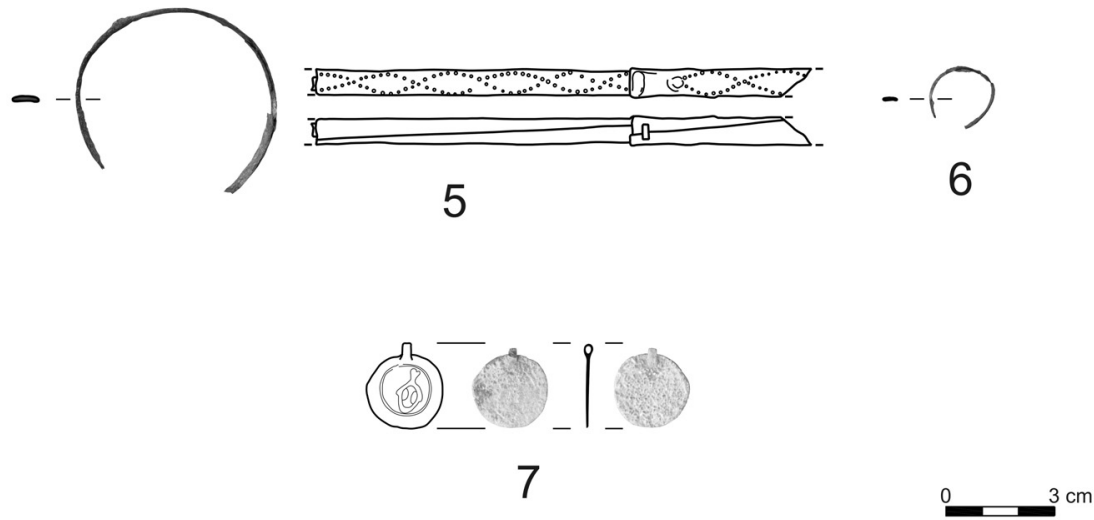

FIGURA 13: Conjunto de elementos de adorno personal en bronce localizados en tres sepulturas del cementerio mudéjar. En la sepultura UE 2022 se hallaron dos pulseras (1 y 2), 2 brazaletes (4 y 5) y un anillo (3). En la sepultura UE 2026 se localizó un pequeño anillo (6), mientras en la sepultura 2002 una pequeña medalla (7).

do 31 inhumaciones, una pequeña porción de un presumible gran espacio funerario.

Todos los enterramientos se localizaron con una disposición SW-NE (de la cabeza a los pies), con la cabeza en algunos casos ladeada hacia el SE.

En algunos casos se ha documentado restos de piezas de metal, seguramente adornos personales, como los de la sepultura UE 2022 , de un individuo infantil de unos 12 años, que conservaba dos pulseras, dos brazaletes y un anillo (Fig. 12). Las dos pulseras en bronce presentan sección circular, una de ellas tiene forma ovalada (Fig. 13,2), mientras la otra es circular (Fig. 13,1). Los dos brazaletes de forma circular tienen sección rectangular, cierre incluido y una decoración repujada de rombos sucesivos (Fig. 13, 4 y 5 ), piezas realizadas a partir de una fina lámina de bronce plegada a modo de cinta. Este mismo enterramiento presenta un pequeño anillo con sello central, sin motivo definido y decoración a ambos lados a base de pequeñas acanaladuras oblicuas (Fig. 13, 3).

Otro elemento de adorno personal, localizado en la sepultura UE 2026, es un pequeño fragmento de anillo en bronce con una estrecha lámina (Fig. 13, 6), perteneciente a una mujer adulta inhumada en decúbito supino.

Por último, en la sepultura UE 2002 de un individuo de 12 a 18 meses de vida, se documentó una medallita de bronce. Consta de dos partes, un pequeño óvalo de forma circular, en cuyo anverso se puede observar vagamente, debido al proceso de oxidación, un motivo ovalado en relieve enmarcado en una orla circular concéntrica al margen, mientras en el reverso no se observa motivo alguno. La segunda parte es el propio colgante hecho a modo de cinta de sección plana que se empalma al óvalo por la parte superior (Fig. 13, 7). 
Se seleccionaron dos muestras de hueso para su análisis de Carbono 14, muestras que fueron enviadas a los laboratorios Beta Analytic Radiocarbon Dating Laboratory, en Miami (Florida-EEUU). La primera muestra, un fragmento de peroné derecho perteneciente a un individuo de unos 12 años inhumado en decúbito lateral derecho, en concreto, la sepultura UE 2022, el que presentaba un ajuar especial con pulseras, brazaletes y un anillo (Fig. 12). La segunda muestra fue un fragmento de fémur izquierdo que pertenecía a un individuo masculino inhumado en decúbito supino (sepultura 2031). De esta manera, se pretendía averiguar si había diferencia cronológica entre los individuos claramente enterrados en decúbito lateral derecho y los enterrados en decúbito supino. Los resultados de los análisis han sido los siguientes:

$1^{\text {a }}$ muestra 2022: $420 \pm 40$ b.p. $=$ cal. $1440-$ 1480 d.C. (Beta-218651, hueso).

$2^{\text {a }}$ muestra $2031: 570 \pm 40$ b.p. $=$ cal. 1390 1420 d.C. (Beta-218652, hueso).

Esta necrópolis bajomedieval en la que se han hallado tanto inhumaciones en decúbito lateral derecho, como otras en decúbito supino, con sus cabezas mirando hacia el Sureste, pertenece a grupos de población musulmana bajo dominio cristiano o de individuos conversos (ya que en numerosos casos, la conversión -en ocasiones forzosa- no implicaba el abandono de costumbres religiosas, lo que se hacía especialmente evidente en la vida privada y en todo lo que afectaba al momento de la muerte). Se demuestra que nos encontramos ante grupos de población islámica que tratan de mantener sus costumbres religiosas (incluyen un ceremonial y un ritual funerario concreto) en un ambiente ya claramente hostil a los mismos.

Por consiguiente, se confirma que en el área excavada de la necrópolis nos encontramos con niveles de enterramientos más o menos contemporáneos, con una diferencia máxima de 50 a 60 años, sin existir diferencia cronológica evidente en relación con el tipo de ritual, si es enterrado en decúbito supino o en decúbito lateral derecho.

En definitiva, remarcar que nos hallamos ante un cementerio mudéjar encuadrado cronológicamente entre los siglos XIV-XV, que se sitúa en las afueras del núcleo urbano y justo al lado de uno de los caminos de salida de la ciudad, colindando con el denominado "raval", núcleo de población mudéjar que se localizaría en el actual barrio de San Joaquín, de origen feudal (s. XIV) (Fig. 4).
Informaciones orales, así como la reciente localización de restos humanos al Sur de la caIle Santa Anastasia, nos confirman que estamos dentro de los límites de un gran cementerio mudéjar. Así a la altura del $n^{\circ} 17$ y 19 de dicha calle, unos $70 \mathrm{~m}$. al Sur de la Plaza de Pare Palau (Fig. 5), tras el derribo de un edificio anterior, se han hallado en los perfiles del solar restos humanos de al menos 6 individuos orientados de SW a NE y con diferentes posiciones -3 en posición de decúbito lateral derecho, 1 en posición de decúbito supino y 3 en posición indeterminada-. Este gran cementerio (Fig. 4 y 5) ocuparía todo el montículo existente entre el antiguo hospital (plaza Pare Palau) al Norte; el final de la calle Santa Anastasia al Sur; mientras el límite hacia el Este vendría a ser la mitad oriental del jardín del hospital excavado, en la ladera recayente al "barranquet"; y por el Oeste se conoce la existencia de restos encontrados al construir las casas incluso recayendo a Poniente de dicho montículo (Menargues, 2004, 236).

\section{EL MUNDO FUNERARIO}

Para entender las características de un cementerio islámico, antes debemos conocer su ritual funerario. El mismo se describe en los textos clásicos, como los preceptos marcados por El Corán o los libros de liturgia musulmana, especialmente los inspirados en la doctrina del jurista Malik ibn Anas $^{3}$, de los que se conservan diversos ejemplares de época morisca. Ritual que coincide, al menos en sus aspectos materiales, con los resultados que nos proporciona la arqueología.

Cuando un musulmán está a punto de morir, según la doctrina malikí, se procede a colocarlo sobre el lado derecho, mirando a la Meca, en la misma posición que debe tener en el sepulcro.

Una vez fallecido el difunto, se le cierran los ojos y se pasa a lavar el cuerpo varias veces con agua (siempre en número impar). El agua puede estar aromatizada con alcanfor o almizcle, o cocida con malvavisco, acedre u otras plantas. Este agua perfumada se utilizaba en el último lavado. Es preceptivo iniciar el lavado del cuerpo por el costado derecho y seguir por las partes sujetas a la ablución ritual (manos, pies y cara).

\footnotetext{
3. Jurista musumán (710-795), que codificó el derecho consuetudinario de Medina, al que incorporó conceptos religiosos y morales. Su escuela, hizo especial hincapié en la Tradición.
} 
Seguidamente se procede al amortajamiento del cadáver con un sudario, entre las piezas del vestuario se podían colocar sustancias aromáticas, como aloe, ámbar o almizcle, mezclado con el alcanfor depositado sobre los oídos, nariz y piel.

El velatorio se evita, pues el musulmán debe llegar lo antes posible a la tierra. El cadáver se coloca sobre unas parihuelas, cubierto de un manto y a veces con ramas y es transportado de forma precipitada. Suele pasar junto a la mezquita, donde se le ora brevemente. La comitiva, en la mayoría de los casos, sólo hombres, se dirige al cementerio mientras todos van cantando suras del Corán. Una vez en el cementerio, el cadáver es colocado en la fosa sin ataúd, sobre la tierra mirando hacia la Meca (Cara, 1993, 87).

Las fosas no debían ser más profundas que la cintura de un hombre y debían excavarse en la misma tierra, sin obra de yeso, ni fábrica en la que se emplee el barro, debían cubrirse con lajas de piedra, adobes o tablas de madera, para que no entre tierra en el interior de la misma. Estos últimos preceptos se cumplen en el caso del cementerio de Crevillent, donde no se ha documentado obra en las fosas, y sí, una sepultura con lajas (UE 2030) y otra con restos de una posible tapa de madera (sepultura UE 2011). Por su parte, la superposición de fosas constatadas en este espacio funerario (Fig. 9) no es la preceptiva según los cánones religiosos, pero como ocurre en otros tantos cementerios islámicos, la necesidad de espacio obliga a reaprovechar el área cementerial de una forma más intensiva.

A grandes rasgos, como indica Guillermo Roselló (1992, 163), debemos saber que la deposición del cadáver se realiza con un sistema rígido y el vaso que conserva el cadáver del creyente, que será respetado y reverenciado, es accesorio, pues lo importante es el paso al más allá, para poder alcanzar en el paraíso la compensación que merece el creyente. Este hecho, hace que las diferencias sociales de los individuos enterrados por el rito musulmán sean muy difíciles de discernir; dicha uniformidad en los enterramientos islámicos sólo nos sirve para distinguir lo islámico de lo cristiano.

En cuanto a la señalización de las sepulturas, si las hubo en la "maqbara" de Crevillent no se han hallado, normalmente en las necrópolis islámicas las sepulturas se señalan en su cabecera y, en ocasiones, en los pies, utilizando una teja clavada verticalmente, o bien colocando una piedra alargada, también vertical, o un sillar de similares características (Carmona, 2005, 96).
En cuanto al emplazamiento de los cementerios, en la mayoría de los casos se localizan extramuros de los núcleos urbanos, a los lados de los caminos principales de la ciudad y próximos a las puertas de la misma. No solían estar delimitados por un muro de cierre y eran considerados lugares sagrados donde no se podía cultivar ni construir. Es normal que se ubiquen en ladera, e incluso próximos a una rambla, que le sirve de límite, como es el caso del cementerio que nos ocupa, que colinda al Este con el conocido "barranquet" (entre la actual calle Higueras y la calle Gabriel Miró) (Fig. 4).

Esta localización en ladera y próximos a una rambla es generalizada en los cementerios islámicos documentados en ciudades como Córdoba (Casal et alii, 2006, 270), Málaga (Peral, 1995, 18), Granada o la mayoría de los cementerios de Lorca (Murcia) (Ponce, 2000, 118-119).

El cementerio islámico de Crevillent, es una "maqbara" mudéjar situada fuera de la ciudad y en el entorno del Raval, núcleo islámico creado tras la conquista cristiana en el actual barrio de San Joaquín (Fig. 4). El dominio ya es cristiano, aunque las costumbres de la población musulmana son permitidas en los primeros siglos tras la conquista. En el ritual funerario vemos cómo se combina la colocación del cadáver en decúbito lateral derecho mirando a la Meca, típico ritual islámico, con otros individuos colocados en decúbito supino, aunque con sus cabezas ladeadas hacia el Sureste.

A diferencia de la población islámica, la cristiana se suele enterrar en las iglesias, por lo que los cementerios bajomedievales y modernos extramuros son siempre de población mudéjar o morisca, como el caso que aquí analizamos.

Las comunidades mudéjares estaban compuestas por la población islámica que permaneció en nuestras ciudades tras la conquista cristiana y que continúo viviendo bajo las costumbres y tradiciones islámicas hasta bien entrado el siglo $\mathrm{XVI}$, en concreto 1525, cuando dicha población fue obligada a bautizarse, a partir de un decreto promulgado por Carlos $\mathrm{V}$, denominándose a partir de dicho momento moriscos, los cuales fueron expulsados definitivamente en 1609 , bajo el reinado de Felipe III.

En el entorno más próximo contamos con dos cementerios de similares características al de Crevillent excavados recientemente en Novelda y Petrer.

La necrópolis mudéjar-morisca de Novelda se localiza al Suroeste del núcleo medieval, en una de las salidas de la ciudad, en el denominado "Portal de Sant Roc". En dicha área y tras diver- 
sas actuaciones arqueológicas en varios solares, entre las calles Agustina de Aragón, San José, Emilio Castelar y calle Colón, se han exhumado un número importante de inhumaciones, la mayoría enterramientos en fosa simple con individuos enterrados en decúbito supino o en decúbito lateral derecho, con una amplia cronología entre los siglos XIV y XVI. Es curioso comprobar cómo en un área de la necrópolis, en su nivel más superficial, aparecen sepulturas en cista, claramente de su fase morisca. (Navarro, 2004, 167-194).

Por otra parte, el cementerio mudéjar de Petrer se halla en el área Sureste del recinto urbano medieval, fuera del mismo, en la zona que ocupa actualmente el Passeig de l'Esplanada, en la ladera del montículo donde se asentaba la Ermita de Sant Bonifaci. De nuevo, estamos ante un cementerio mudéjar de gran extensión con sepulturas en fosa simple, cuyos cadáveres son colocados tanto en decúbito supino como en decúbito lateral derecho. Los estudios antropológicos de las inhumaciones han dado como resultado que se trata de una comunidad con una tipología física próxima a los mediterráneos gráciles, que algunos la asocian a comunidades euroafricanas. En cuanto a sus patologías, la artrosis está muy extendida entre los individuos adultos y la salud bucal es muy deficiente. También se registran traumatismos como consecuencia del trabajo, accidentes o agresiones (Navarro, 2005, 32-40).

Otro ejemplo de cementerio mudéjar valenciano, lo tenemos en Pedreguer, con el $\mathrm{Ce}$ menteri dels Fossarets perteneciente a la alquería de dicha población, donde se combinan las fosas con cubierta de piedra y de teja; necrópolis con una amplia cronología entre los siglos XIV y XVI (Costa, 2004, 123-136). También se tiene conocimiento de muchas necrópolis moriscas valencianas, ya del siglo XVI, en los alrededores de Gandía, como el cementerio de la alquería de Bellreguard (Martí y Cardona, 1992, 397-405), donde coexisten enterramientos bajo cubierta de teja con aquellos realizados en fosa simple; al igual que ocurre en otros puntos de la Marina como en Parcent, Confrides, o más al norte, en las ciudades de Paterna o Manises (Valencia).

\section{A MODO DE CONCLUSIÓN}

Desde el punto de vista de la arqueología medieval funeraria, este trabajo supone un importante avance respecto a las carencias generalizadas en los estudios de las excavaciones de áreas cementariales islámicas, en ellas se constatan pro- blemas para adscribir cronológicamente estos espacios, debido a la simplicidad en las sepulturas, ausencia de ajuares, carencia de epigrafía y de análisis antropológicos básicos (Casal et alii, 2006, 260).

En nuestro caso, y aunque estemos ante una excavación parcial y no un cementerio completo, ya tenemos datos fehacientes de la cronología de los individuos enterrados, gracias a las dataciones efectuadas en los restos óseos de dos sepulturas, que nos llevan a fechar el área funeraria entre los siglos XIV-XV, y por el ritual realizado con dichos difuntos, sabemos que se trata de poblaciones musulmanas -mudéjares-. Además, en este mismo trabajo se anexa el estudio osteoarqueológico de cada enterramiento, lo que nos ha permitido conocer de forma rigurosa, sus edades, sexos, costumbres alimenticias, más bien sus carencias, sus enfermedades más generalizadas, relacionadas con sus duras jornadas laborales, como artrosis y lesiones musculares, elementos todos ellos que nos indican claramente que nos hallamos ante grupos de población de contexto rural.

Lo realmente significativo a nivel local de esta excavación es que ha hecho posible avanzar en el conocimiento del urbanismo medieval de Crevillent, suponiendo todo un hito en la arqueología urbana crevillentina, al documentar y delimitar en parte un cementerio mudéjar de los siglos XIV-XV, que pudo extender su uso con toda seguridad hasta la expulsión de los moriscos en 1609. Espacio funerario, totalmente vinculado al raval, núcleo de población islámico localizado al Norte de la Vila Vella (Fig. 4).

A partir de futuras intervenciones arqueológicas y otros trabajos de archivo, esperemos poder definir en mayor medida este cementerio y ampliar el conocimiento de otros elementos urbanísticos de época medieval de Crevillent, que hasta el día de hoy nos son bastante desconocidos.

Crevillent, septiembre de 2007
Julio Trelis Martí

Vial del Parc s/n.

03330 Crevillent

jtrelis.marqcrev@telefonica.net

José Ramón Ortega Pérez

Daniel Tejerina Antón

Marco Aurelio Esquembre Bebia

Empresa de Arqueología,

Restauración y Gestión del Patrimonio

Avda. Rodalet $23 \mathrm{~A}$

03690 San Vicente del Raspeig

arpapatrimonio@telefonica.net 


\section{BIBLIOGRAFÍA}

AZUAR RUIZ, R., 1995: "Una década de arqueología medieval en el País Valenciano", Actes de les Jornades d'Arqueologia d'Alfàs del Pi, 213-236, Valencia.

CASAL, M.T.; LEÓN, A.; LÓPEZ, R.; VALDIVIESO, A.; SORIANO, P.J.; 2006: "Espacio y usos funerarios en la Qurtuba islámica", Anales de Arqueología Cordobesa, n 17, vol. II, 257-290.

CARA BARRIONUEVO, L., 1993 : "La civilización islámica”. Historia de Almería, $n^{\circ} 3$, Almería.

CARMONA ÁVILA, R., 2005: "El Palenque (Pliego de Córdoba): introducción a su evolución urbana según la aportación de la arqueología y una revisión de las fuentes bibliográficas y documentales." Antiquitas, 17, 83-136.

COSTA CHOLBI, P., 2004: "La Necròpoli Medieval dels Fossarets de Pedreguer", Aguaits. Revista d'Investigació $i$ Assaig, 21, 123-136.

FERRER I MALLOL, M. T., 1987: "Els sarraïns de la corona catalano-aragonesa en el segle XIV. Segregacio y discriminacio", Anuario de Estudios Medievales, Anex 16, Barcelona.

FERRER I MALLOL, M. T., 1988a: "Les aljames sarraïnes de la Governacio d'Oriola en el segle XIV", Anuario de Estudios Medievales, Anex 19, Barcelona.

FERRER I MALLOL, M. T., 1988b: "La frontera amb l'islam en el segle XIV. Cristians i sarraïns al País Valencia”, Anuario de Estudios Medievales, Anex 18, Barcelona.

GARRIDO I VALLS, D., 1997: "Elx i Crevillent sota la senyoria de la ciutat de Barcelona", La Rella, 11, 11-36.

GARRIDO I VALLS, D., 2003: "Les comunitats musulmanes d'Elx i Crevillent sota la senyoria de Barcelona", La Rella, 16, 11-36.

GOZÁLVEZ PÉREZ, V., 1983: Crevillente. Estudio urbano, demográfico e industrial, Alicante.

GUICHARD, P., 1976: Un señor musulmán en la España Cristiana: el "ra'is" de Crevillente (1243-1318)", Crevillente.

HINOJOSA MONTALVO, J., 1989: "Crevillente: una comunidad mudéjar en la Gobernación de Orihuela en el siglo XV", IV Simposio Internacional Mudejarismo, Teruel, 307317.

LAPEYRE, H., 1959: Géographie de l'Espagne morisque, París.

LĖVI-PROVENÇAL, E., 1938: La Péninsule Ibérique au Moyen Âge d'aprés le Kitab al-Rawd al Mi'tar fi habar al-aqtar d'Ibn al Mun'im al-Himyari, Leiden.
MARTÍ, J. y CARDONA, J., 1992: "La necrópolis de Bellreguard y otros datos sobre necrópolis moriscas valencianas", III Congreso de Arqueología Medieval Española (Oviedo, 1989), t. II, 397-405.

MENARGUES, J., 2002: "Muralles, defenses i barris del crevillent medieval (I)", Revista de Moros y Cristianos, 260-273.

MENARGUES, J., 2004: "Els carrers de Crevillent. De Matxa a la Creu de Ruïsa, passant per la Vereda de les Fotges. Una ullada reivindicativa a la història i el nom d'uns quants carrers crevillentins", Revista de Semana Santa, LXVII, 231-241.

MENARGUES, J., 2005: "Muralles, defenses i barris del crevillent medieval (II)", Revista de Semana Santa, LXVIII, 249-255.

MIZAL, J. A., 1989: Los caminos de al-Andalus en el siglo $X I$, Madrid.

MONTESINOS, J.: "Historia de Crevillente. Año 1740", Compendio Histórico Oriolano, ejemplar manuscrito.

NAVARRO POVEDA, C., 1995: "La necrópolis bajomedieval de Novelda (Alicante). Resultados de la excavación de urgencia", Boletín de Arqueología Medieval , $n^{\circ}$ 9, 223-236.

NAVARRO POVEDA, C., 2000: "El cementerio mudéjar del Portal de San Roc", Betania, 95-98.

NAVARRO POVEDA, C., 2004: "Aportaciones arqueológicas al estudio de la villa medieval de Novelda”, II Jornadas de Arqueología Medieval: De la Medina a la Vila, 167-194.

NAVARRO POVEDA, C., 2005: "La Vila de Petrer: De la Conquesta Cristiana a l'Expulsió dels Moriscos”, en JOVER MAESTRE, F.J.: Vida i Mort a Petrer, 32-40. Petrer.

PERAL BEJARANO, C., 1995: "Excavación y estudio de los cementerios urbanos andalusíes. Estado de la cuestión", en TORRES, M. P. y ACIÉN, M. (Eds): Estudios sobre cementerios islámicos andalusíes, 11-36, Málaga.

PONCE GARCÍA, J., 2002: "Los cementerios islámicos de Lorca. Aproximación al ritual funerario", Alberca. Revista de la Asociación de Amigos del Museo Arqueológico de Lorca, 1,115-147.

ROSSELLÓ BORDOY, G., 1992: “Almacabras, ritos funerarios y organización social”, III Congreso de Arqueología Medieval Española (Oviedo, 1989), t. I,151-168.

TRELIS MARTI, J., MOLINA MAS, F. J., ORTEGA PÉREZ, J. R. y PEDRAZ PENALVA, T., 2004: "Arqueología urbana. Recientes excavaciones en la Vila Vella", Revista de Moros y Cristianos, 242-247.

TRELIS MARTÍ, J. y MOLINA MAS, F. A., 2001: "Crevillent: arqueología y urbanismo", Revista de Moros y Cristianos, 206-208. 